\title{
A Review: Pharmaceutical Wastewater Treatment Technology and Research in China
}

\author{
Xin Li \\ Tianjin Research Institute for Water Transport \\ Engineering, Key Laboratory of Environmental \\ Protection Technology on Water Transport, M.O.T. \\ Tianjin, China \\ lixin1609@tju.edu.cn
}

\author{
Guoyi Li \\ Tianjin Research Institute for Water Transport \\ Engineering, Key Laboratory of Environmental \\ Protection Technology on Water Transport, M.O.T. \\ Tianjin, China \\ lguoyi@126.com
}

\begin{abstract}
The origin and character of pharmaceutical wastewater were summarized in this paper. And some popular disposal technologies used in wastewater treatment of pharmacies were introduced, such as physicochemical disposal process, bio-chemical disposal process and process of deeply oxidation at elevated temperature. All kinds of waste categories, respectively, described the similarities and differences in their approach. It contained the sources of this waste water, the most suitable method and cost. Several mainstream in articles on this treatment method, for a detailed discussion of the process of adaptation to their overall costs and technical bottlenecks were summarized. Meanwhile, operating parameters, residence time, reaction temperature, catalyst, secondary pollution and other technical details are within the scope of the discussion. At last, it gives a prospect of the market of pharmaceutical wastewater in our institutions.
\end{abstract}

Keywords- pharmaceutical wastewater; advanced oxidation; disposal costs; bio-treatment; photo-catalytic degradation.

\section{INTRODUCTION}

Pharmacy industry is a high-tech, high investment, high efficiency which recognized as a most promising international industry [1]. At present, China has more than 4,000 pharmaceutical enterprises [2]. It can produce about 1500 kinds of chemical raw materials, chemical preparations as well as more than 4,000 species, and the total output of about 1.935 million tons in 2009 [3]. The pharmaceutical industrial output value reached 1.04 trillion yuan. However, along with pharmacy industry continues to develop, it leads to environmental problems [4]. Currently, it is one of 12 national environmental planning key governance sectors [5]. Some statistics said that pharmacy industry output accounted for $1.7 \%$ of GDP while the country's total water emissions accounted for $2 \%$ of sewage discharge [6]. Pharmaceutical wastewater has a composition of complex and it contained many kinds of organic pollutants in high concentrations, $\mathrm{COD}, \mathrm{BOD}_{5}$, $\mathrm{NH}_{3}-\mathrm{N}$ and high levels of suspended solids, color depth, toxicity and other features [7]. According to incomplete statistics, Chinese pharmaceutical exhaust emissions per year (standard state) are about 1 billion cubic meters, which contains about 100,000 tons of harmful substances [8]. Wastewater discharge is about 500,000 cubic meters per day, and waste and emissions of about 100,000 tons per year with the most polluted pharmacy chemical synthesis [9]. This paper focuses on the details of these treatment methods and pharmaceutical wastewater [10].

\section{CHARACTERISTICS OF PHARMACY WASTEWATER}

According to distinguish between pharmaceutical products, this waste is divided into bio-pharmaceutical, chemical, pharmaceutical and herbal production waste water [11].

\section{A. Properties of Bio-pharmaceutical Waste}

Bio-pharmaceutical wastewater containing mainly mycelium, residual nutrients, metabolites and organic solvents. The current process is mainly used for the production of bio-pharmaceutical antibiotics. A high concentration of organic matter in the wastewater, COD is up to $5000-20000 \mathrm{mg} / \mathrm{L}, \mathrm{BOD}_{5}$ is up to $2000-10000 \mathrm{mg} / \mathrm{L}$, SS concentration can reach $5000-23000 \mathrm{mg} / \mathrm{L}$ while TN reach $600-1000 \mathrm{mg} / \mathrm{L}$. China currently has more than 300 producers of antibiotics. It can produce more than 70 varieties, yields of $20 \%-30 \%$ of the world. And for each 1t products, high concentrations of wastewater discharge reached $150-850 \mathrm{~m}^{3}$, thus causing serious environmental pollution. Common bio-pharmaceutical waste physicol chemical properties as shown in the following TABLE I.

TABLE I. COMMON BIO-PHARMACEUTICAL WASTE PHYSICOCHEMICAL PROPERTIES

\begin{tabular}{cc|cc}
\hline Item & Concentration & Item & Concentration \\
\hline COD $(\mathrm{mg} / \mathrm{L})$ & $2000-10000$ & $\mathrm{SS}(\mathrm{mg} / \mathrm{L})$ & $200-500$ \\
Chromaticity & $500-1000$ & $\mathrm{BOD}_{5}(\mathrm{mg} / \mathrm{L})$ & $1000-2500$ \\
Temp. $\left({ }^{\circ} \mathrm{C}\right)$ & $25-80$ & $\mathrm{TP}(\mathrm{mg} / \mathrm{L})$ & $50-250$ \\
$\mathrm{pH}$ & $4-8$ & $\mathrm{TN}(\mathrm{mg} / \mathrm{L})$ & $500-1500$ \\
\hline
\end{tabular}

B. Composition and Properties of Chemical and Pharmaceutical Waste

The main production processes of pharmy are chemical and pharmaceutical chemistry. Due to its materials complex, multi-step reaction, resulting in low conversion rate and the raw product with sufferring serious losses. Such a wide variety of wastewater containing toxic and hazardous chemicals, such as steroids, nitro compounds, anilines, piperazine and fluorine, mercury, chromium copper, and organic solvents which contain ethanol, benzene, chloroform, petroleum ether and other organic compounds, metals and waste acid and other pollutants, it can cause serious trace pollution problems. However, because synthesized pharmaceutical 
industry is more complex, a pharmaceutical company's product range is often not the one, so the wastewater pollutants contained in the synthesis of pharmaceutical companies the situation is more complicated. According to statistics show that domestic surveillance, COD concentration range of chemical synthetic pharmaceutical companies in $432-32140 \mathrm{mg} / \mathrm{L}$; $\mathrm{BOD}_{5}$ concentration is range of $300-8000 \mathrm{mg} / \mathrm{L}$; SS concentration is range of 80 $2318 \mathrm{mg} / \mathrm{L} ; \mathrm{NH}_{3}-\mathrm{N}$ concentration range in $4.8-1764 \mathrm{mg} / \mathrm{L}$. Common chemical and pharmaceutical wastewater properties as shown in the following TABLE II.

TABLE II. COMMON CHEMICAL AND

PHARMACEUTICAL WASTEWATER PROPERTIES

\begin{tabular}{cc|cc}
\hline Item & Concentration & Item & Concentration \\
\hline COD $(\mathrm{mg} / \mathrm{L})$ & $1000-10000$ & $\mathrm{SS}(\mathrm{mg} / \mathrm{L})$ & $200-500$ \\
Chromaticity & $500-1000$ & $\mathrm{BOD}_{5}(\mathrm{mg} / \mathrm{L})$ & $500-2500$ \\
Temp. $\left({ }^{\circ} \mathrm{C}\right)$ & $25-80$ & $\mathrm{TP}(\mathrm{mg} / \mathrm{L})$ & $50-250$ \\
$\mathrm{pH}$ & $1-6$ & $\mathrm{TN}(\mathrm{mg} / \mathrm{L})$ & $500-1500$ \\
$\mathrm{SO}_{4}{ }^{2-}(\mathrm{mg} / \mathrm{L})$ & $5000-25000$ & Chlorobenzenes & $500-3000$ \\
$\mathrm{Zn}^{2+}(\mathrm{mg} / \mathrm{L})$ & $1000-5000$ & $(\mathrm{mg} / \mathrm{L})$ & $500-1000$ \\
$\mathrm{Salts}(\mathrm{mg} / \mathrm{L})$ & $10000-25000$ & Aniline $(\mathrm{mg} / \mathrm{L})$ & $1-100$ \\
\hline
\end{tabular}

\section{Chinese Traditional Pharmaceutical Waste}

Chinese traditional medicine and folk medicine are our medical science features and advantages. As of 2014, these industrial output value is of 577.2 billion yuan accounting for $27 \%$ of the entire pharmaceutical industrial output value. Chinese traditional medicine production has many processes with washing, cooking drugs, purification separation, evaporation and concentration processes for producing wastewater to be discharged. It comprises a washing wastewater, the separation of water, evaporation condensate, loss of liquid water. Curruntly, these wastewater are mainly a variety of traditional Chinese medicine decoction natural biological organic matter, such as organic acids, anthraquinone, lignin, alkaloids, tannins, tannins, proteins, carbohydrates, starch. Its water quality volatile, additional water may also contain alcohol used in preparing medicine and other organic solvents. Common Chinese traditionnal pharmaceutical wastewater properties as shown in the following TABLE III.

TABLE III. COMMON CHINESE TRIDITIONAL PHARMACEUTICAL WASTEWATER PROPERTIES

\begin{tabular}{cccc}
\hline Item & Concentration & Item & Concentration \\
\hline COD $(\mathrm{mg} / \mathrm{L})$ & $1000-10000$ & $\mathrm{SS}(\mathrm{mg} / \mathrm{L})$ & $200-500$ \\
Chromaticity & $500-1000$ times & $\mathrm{BOD}_{5}(\mathrm{mg} / \mathrm{L})$ & $500-2500$ \\
Temperature & $25-80^{\circ} \mathrm{C}$ & $\mathrm{TP}(\mathrm{mg} / \mathrm{L})$ & $50-250$ \\
$\mathrm{pH}$ & $1-6$ & $\mathrm{TN}(\mathrm{mg} / \mathrm{L})$ & $500-1500$ \\
Cyclic & Trace & Phenol & Trace \\
Heterocyclic & Trace & $\begin{array}{c}\text { Unsaturated } \\
\text { fatty-acids } \\
\text { Ontibiotic } \\
(\mu \mathrm{g} / \mathrm{L})\end{array}$ & Trace \\
Organochlorine & Trace & $1-100$ \\
\hline
\end{tabular}

\section{PHARMACY WASTE PHY-CHEMISTRY TREATMENT}

\section{A. Coagulation and Sedimentation}

Current research for pharmaceutical wastewater treatment technology domestic and abroad are often based on high concentrations of the most representative, most pollutant of bio-fermentation pharmacy, bio-chemical, pharmaceutical and other produce. Biodegradable organic waste is the main object, commonly used mainly for processing physic-chemical, biological method and hightemperature oxidation depth. Physic-chemical treatment is not only as a pre-biological treatment processes, and sometimes also is a post-treatment process alone or pharmaceutical wastewater treatment processes. At the same time, integrated pharmaceutical wastewater treatment currently used methods are mainly materialized following: coagulation and sedimentation, flotation, adsorption, chemical oxidation (Fenton reagents, wet oxidation, etc.), electrolysis (Fe-C micro-electrolysis) and so on.

Materialized in economical methods of coagulating sedimentation method is preferred. Coagulant to the water, wastewater colloidal particles can lose stability, cohesion and large particles sink. This method is usually treated by coagulation, not only can effectively reduce the concentration of pollutants, and biodegradability of wastewater can be improved.

\section{B. Flotation}

Flotation using highly dispersed tiny bubbles as a carrier to adhere to the wastewater pollutants. With less dense than water, it realized the water and float to the solid-liquid or liquid-liquid separation. Flotation applicable pretreatment high suspended solids content of wastewater, with less investment, low energy consumption, simple process, and easy maintenance.

\section{Adsorption Method}

Adsorption method is the use of porous solids from wastewater in one or several pollutants, to recover or remove contaminants, so that waste water is purified approach. In the pharmaceutical wastewater treatment, commonly soot or carbon adsorption wastewater pretreatment production medicine, lincomycin, such as paracetamol, significant reduction in COD, while removing waste water color and odor.

\section{Fe-C Method of Micro-electric Field}

Production in Fe-C is as a pre-processing step pharmacy wastewater. In the process flow, after pretreatment of wastewater biodegradability greatly improved, the effect is obvious. Plus the use of inexpensive $\mathrm{Fe}^{2+}$ catalyst such wastewater treatment, COD removal can reach the second part of the industry's highest pollutant emission concentration, and this method over other many methods is economic and stable.

\section{E. Fenton Method}

Pretreatment pharmaceutical wastewater using Fenton's reagent, COD removal rate is about $40-50 \%$. A pharmaceutical factory in Wuhan of pharmaceutical wastewater treatment using this method. And the decolonization rate achieved $100 \%$. The COD removal efficiency is of $92.3 \%$ in results. Comprehensive comparison of all of the above approach is as follows in TABLE IV.

TABLE IV. COMPARISON OF SEVERAL PHYSICAL-CHEMICAL TREATMENT METHOD

\begin{tabular}{cc|cc}
\hline Treatments & Efficiency & Processing & Costs \\
\hline Coagulation & $50-80 \%$ & Pretreatment & Low \\
sedimentation & $70-85 \%$ & Pretreatment & Low \\
Flotation & $80 \%$ & $\begin{array}{c}\text { Pretreatment } \\
\text { Secondary } \\
\text { processing }\end{array}$ & Low \\
Adsorption & $60-75 \%$ & Low \\
Fe-C & $60-95 \%$ & $\begin{array}{l}\text { Secondary } \\
\text { processing }\end{array}$ & Low \\
Fenton & $85-99 \%$ & Advanced treatment & High \\
Photo-catalytic & & &
\end{tabular}




\section{Biological TREATMENT}

\section{A. Aerobic Biological Treatment Technology}

There are aerobic biological treatment process microbial treatment, anaerobic treatment and anaerobicaerobic combined treatment process. Common aerobic biological wastewater treatment facilities have conventional activated sludge method. It contained high load activated sludge, oxidation ditch, SBR, CASS, CAST, ICEAS, UNITANK, DAT-IAT, MSBR, BAF, etc. In terms of process technology evolution, domestic pharmaceutical wastewater aerobics biological treatment is first used for aerobic activated sludge process represented; the mid-1990s, SBR, ICEAS, CASS technology has made relatively good results; and for the 21 st century, three oxidation Ditch, UNITANK and MSBR pharmaceutical wastewater treatment and other new technology has made continuous exploration and applications. It was often used for the easily-biological wastewater and the ratio of $\mathrm{BOD}_{5} / \mathrm{COD}$ was more suitable to be more appropriate.

\section{B. Anaerobic Process}

At present, domestic pharmacy treatment of high concentration organic wastewater, anaerobic fermentation is basically approach. Compared with the aerobic treatment, anaerobic treatment of high concentration organic wastewater typically has the following advantages: high organic loading; sludge production is low, easily biological sludge dewatering; fewer nutrients needed; without aeration, low energy consumption; can produce biogas energy recovery; suitable for a wider range of temperature; long active anaerobic sludge retention time. It was often used in the non-biological wastewater.

\section{Combination Process}

Anaerobic and aerobic treatment methods have advantages and disadvantages, the combination of two processes together, and their respective advantages to get promoted, get inadequate remedy. Common combination process route micro electrolysis-anaerobic hydrolysis acidification process-SBR series, pretreatment-UBFcontact oxidation-BAF treatment processes, hydrolysis acidification-UASB-SBR processes are often process route. It was also often used in non-biological wastewater. Compare the pros and cons of these three processes are as follows in TABLE V.

TABLE V. ANAEROBIC, AEROBIC AND COMBINED PROCESS OF THE PROS AND CONS.

\begin{tabular}{|c|c|c|c|}
\hline Treatments & Aerobic & Anaerobic & Combined \\
\hline $\begin{array}{l}\text { Adaptation } \\
\text { Temp. }\end{array}$ & $\begin{array}{c}\text { Adapt high } \\
\text { Temp. }\end{array}$ & Room Temp. & $\begin{array}{l}\text { Adapt high } \\
\text { Temp. }\end{array}$ \\
\hline Pressure & Atmospheric & Atmospheric & Atmospheric \\
\hline Removal & Thoroughly & $\begin{array}{c}\text { Not } \\
\text { Completely }\end{array}$ & Thoroughly \\
\hline Residence & Few hours & Few hours & Soon \\
\hline $\begin{array}{l}\text { Secondary } \\
\text { Pollution }\end{array}$ & Little & No & No \\
\hline Costs & Low & Low & High \\
\hline
\end{tabular}

\section{HIGH-TEMPERATURE OXIDATION}

\section{A. Wet Air Oxidation (WAO)}

High-temperature oxidation treatment technologies include: Wet Air Oxidation (WAO), supercritical water oxidation technology (SCWO) and incineration. WAO is at a high temperature $\left(150-350^{\circ} \mathrm{C}\right)$ and high pressure $(0.5-$ $20 \mathrm{MPa} . \mathrm{G})$ under air or pure oxygen as the oxidant for the oxidative decomposition of organic pollutants and chemical processes of inorganic or small organic molecules. Operation in the waste liquid and mixed by the high-pressure pressurized air into the air warmed by the heat exchanger after the oxidation reactor, the reaction product obtained after the heat exchanger into the cooling tower heat exchanger heated with continued cooling, and then divided by the sort of gas-liquid separator and liquid, and then sent to the subsequent processing. COD removal is generally wet oxidation of $60 \%-96 \%$, the water cannot be discharged directly WAO treatment, most wet oxidation system used in conjunction with biological treatment systems.

\section{B. Super-critical Water Oxidation Technology (SCWO)}

SCWO The principle is: the water temperature and the pressure was increased to the critical point $\left(\mathrm{Tc}=374^{\circ} \mathrm{C}\right.$, $\mathrm{pc}=22.1 \mathrm{MPa} . \mathrm{G})$ above, the water becomes supercritical water, hydrogen water, no longer exists; After supercritical water leads to oxygen and supercritical water can dissolve excellent, oxidation of organic matter can be carried out in a uniform oxygen-rich phase. Meanwhile, a high reaction temperature $\left(400-600^{\circ} \mathrm{C}\right)$ also accelerate the reaction rate, organic matter in the waste water can achieve high destruction efficiency within a few seconds, and the reaction is fully and completely; Make organic matter into $\mathrm{CO}_{2}, \mathrm{~N}_{2}, \mathrm{H}_{2}$ and $\mathrm{H}_{2} \mathrm{O}, \mathrm{Cl}$ chloride ions into a metal salt, and the nitro group was converted into $\mathrm{N}_{2}, \mathrm{~S}$ is converted to sulfate. This method is somewhat similar to the simple combustion process similar to emit a lot of heat in the oxidation process, once the operating normally, reaction heat can not only meet the heating needs of the wastewater, but also generate a lot of heat for the production.

SCWO for organic matter removal rate is about $99.99 \%$. Therefore, it compared with the traditional approach, with high efficiency, energy saving, no secondary pollution and other significant advantages, is a promising high concentration organic wastewater treatment technology.

\section{Incineration}

Incineration of waste is to be treated with an excess of oxidizing air in the incinerator combustion reaction, so that the pollutants contained in the wastewater at a high temperature oxidative decomposition is destroyed, is an integrated and high-temperature treatment of deep oxidation processes. Incineration can greatly reduce the volume of waste water, the elimination of many of these harmful substances, while the recovery of heat. Thus, for some temporary recovery value method and other methods cannot solve or handle combustible waste is not complete, it is a valid burning. This method enables the complete oxidation of waste into harmless substances, COD removal efficiency of $99.5 \%$. Therefore, suitable for handling high organic content or higher calorific value of waste is widely regarded. Through the organic content of the waste water is less, it may be added to the auxiliary fuel. 
Seen from TABLE VI, supercritical water oxidation and incineration highest COD removal, almost completely removed, and the water after the wet air oxidation process cannot meet emissions standards, the need to follow-up treatment; from an investment point of view, partial incineration investment large, and wet air oxidation technology minimum; operating cost analysis from the point of view, at least supercritical water oxidation, and the largest incineration.

TABLE VI. MERITS OF THE THREE KINDS OF

HIGH-TEMPERATURE PROCESSING METHOD.

\begin{tabular}{|c|c|c|c|}
\hline Treatments & SCWO & WAO & Incineration \\
\hline $\begin{array}{l}\text { Adaptation } \\
\text { Temp }\end{array}$ & $>400$ & $150 \sim 350$ & $1200 \sim 2000$ \\
\hline Pressure & 30MPa.G & 2-20MPa.G & Atmospheric \\
\hline Removal rate & $\geq 99.99 \%$ & $70 \sim 90 \%$ & $99.99 \%$ \\
\hline Catalysts & No & Yes & No \\
\hline Processing time & $\leq 60 \mathrm{~s}$ & $15 \sim 20 \mathrm{~min}$ & $\geq 100 \mathrm{~min}$ \\
\hline $\begin{array}{l}\text { Subsequent } \\
\text { process }\end{array}$ & $\begin{array}{l}\text { Colorless } \\
\text { nontoxic }\end{array}$ & $\begin{array}{l}\text { Colorless } \\
\text { nontoxic }\end{array}$ & NOx \\
\hline Spontaneous & Yes & No & No \\
\hline Costs & 65 Yuan/t & $100 \mathrm{Yuan} / \mathrm{t}$ & 15000 Yuan/t \\
\hline $\begin{array}{c}\text { Initial } \\
\text { Investment }\end{array}$ & $650 \mathrm{M} \mathrm{Rmb}$ & $500 \mathrm{M} \mathrm{Rmb}$ & $1000 \mathrm{M} \mathrm{Rmb}$ \\
\hline
\end{tabular}

\section{CONCLUSIONS}

It extensively carried out high-tech applications in the study of pharmaceutical wastewater treat, its rapid development for the chemical industry and the pharmaceutical industry for high concentration organic wastewater provides a broad application prospects. It can focus on high-temperature, combination treatment technology, deeply oxidation technology to high COD concentration, complex composition, and poor biodegradability of pharmaceutical wastewater as a focus of upgrading industrial restructuring. Play burned advantages waste treatment, in the original engineering experience to develop new technology and high added value with intellectual property, promote the development of domestic pharmaceutical wastewater treatment and disposal. At last, it is a widely optimistic about the growth of new technologies and potential markets.

\section{ACKNOWLEDGEMENTS}

The research work was supported by Construction Technology Project of M.O.T. Grant No.2013328224540, No.2013328224520 and by the Center Welfare Institutes Fundamental Research Funds (TKS130206).

\section{REFERENCES}

[1] Chen X.P and Mi Zh.K, "Physical-Chemical Treatment of PharmAceutical Wastewater Technology and Progress," Anhui Medical and Pharmaceutical Journal, vol. 13(10), pp. 1279-1281, 2009. (in Chinese)

[2] Zhang G.F, Xiao Sh.H and Xiao H.K, "Pretreatment of Berberine Pharmaceutical Wastewater Using Electrochemical Process,' Research of Environmental Sciences, vol. 24(1), pp. 79-85, 2011. (in Chinese)

[3] Zhao Y and Sun T.C, "The Research Process of Pharmaceutical Wastewater Treatment Technology," Journal of Green Science and Technology, vol. 11, pp. 75-78, 2010. (in Chinese)

[4] Li X and Li G.Y, "The Research of High-Salt Organic Liquid Waste Incineration Technology," Advanced Materials Research, vol. 1065-1069, pp. 3219-3222, 2015.

[5] Li X and Shou Y.P, "Crude Oil Shipment Port of Atmospheric Environmental Impact VOCs," Journal of Green Science and Technology, vol. 4, pp. 22-27, 2015. (in Chinese)

[6] Xiao SH.H and Zhang G.F, "Treatlnent of Berberine Pharmaceutical Wastewater Contailling Copper by Bipolarelectrochemical Process," Journal of Environmental Engineering Technology, vol. 1(4), pp. 295-299, 2011. (in Chinese)

[7] Chen J.Q, Shang C and Cai X.L, "Application of Cyclonic Floatation Integrated Technology in Low Oil Content Sewage Treatment," China Petroleum Machinery, vol. 41(9), pp. 62-66, 2013. (in Chinese)

[8] Peng R.Y and Tang X.J, "Oxidation Treatment of Pharmaceutical Wastewater by $\mathrm{O}_{3}$ and $\mathrm{O}_{3} / \mathrm{H}_{2} \mathrm{O}_{2}$," Environmental Scinece \& Technology, vol. 34(3), pp. 85-88, 2011. (in Chinese)

[9] Xiao H, Li J and Zhang Y.G, "Treatment of High Concentration Pharmaceutical Wastewater by Coupling Technique of Electrochemical Oxidation and Internal-Electrolysis," Journal of Tianjin Polytechnic University, vol. 30(1), pp. 55-59, 2011. (in Chinese)

[10] Cui N, Wang G.W and Xu X.CH, "Pretreatment of Fosfomcin Sodium and Berberine Pharmaceutical Wastewater with CWAO," Technology of Water Treatment, vol. 38(2), pp. 72-76, 2012. (in Chinese)

[11] Yao H, Wang Y.K and He Y.S, "Study on Antibiotic and Starch Mixed Wastewater Treatment by Combined Two-phase Anaerobic, Aerobic and Anammox Process," Journal of Environmental Engineering Technology, vol. 3(3), pp. 183-187, 2013. (in Chinese) 